\title{
Coleção Obras Raras de Mato Grosso
}

\author{
Isaac Newton Almeida Ramos \\ Universidade de São Paulo
}

Coleção Obras Raras de Mato Grosso ${ }^{1}$ é um convite à leitura para o leitor interessado na literatura brasileira da primeira metade do século XX. Apresentada em sete volumes, os editores Walnice Vilalva e Carlos Gomes de Carvalho superam os desafios e cumprem a missão de pesquisadores.

Vários docentes da UNEMAT estiveram envolvidos na realização desse trabalho. Inclusive este resenhista que produziu material sobre Manoel de Barros para o site www.literaturamt.com ${ }^{2}$. Dentre as dificuldades enfrentadas pelo grupo, destacam-se: a microfilmagem de originais na Biblioteca Nacional do Rio de Janeiro; a edição de um livro a partir de única fotocópia conhecida (Luz e sombras); a dificuldade de um patrocinador (que levou quase três anos) até que a Secretaria de Estado de Ciência e Tecnologia assumisse efetivamente essa tarefa.

A coleção possui uma apresentação visual na qual se observam cores alegres (laranja, tangerina, carmim, vinho, verde etc.) que formam figuras geométricas. Na capa, à direita, o número do volume seguido do título da obra, nome do autor e uma ilustração. Destaque para as telas de Sebastião Mendes, Joana Castrilon e Mari Bueno. A única que manteve a ilustração da edição anterior

1 BARROS, Feliciano Galdino de. Luz e sombras. Cuiabá: Academia Mato-Grossense de Letras; UNEMAT, 2008 (v. 1). BIANCO FILHO, Francisco. Mirko. Cuiabá: Academia MatoGrossense de Letras; UNEMAT, 2008 (v. 2). MATOS, Lobivar. Areôtorare/Sarobá. Cuiabá: Academia Mato-Grossense de Letras; UNEMAT, 2008 (v. 3). MESQUITA, José de. Piedade. Cuiabá: Academia Mato-Grossense de Letras; UNEMAT, 2008 (v. 4). MARIEN, Alfredo. Era um poiaeiro. Cuiabá: Academia Mato-Grossense de Letras; UNEMAT, 2008 (v. 5). Vozes femininas: Amália Verlangieri; Arlinda Morbeck; Vera Randazzo. Cuiabá: Academia Mato-Grossense de Letras; UNEMAT, 2008 (v. 6). RIBEIRO, Luis Sabóia. Caçadores de diamantes. Cuiabá: Academia Mato-Grossense de Letras; UNEMAT, 2008 (v. 7).

2 Esse site especializado em Literatura Mato-Grossense foi ao ar pela primeira vez em 08/05/2007. 
foi Caçadores de diamantes (v. 7). No canto esquerdo, uma espécie de marcador de página, na vertical consta o logotipo Coleção Obras Raras da Literatura MatoGrossense (diferente do que consta na folha de rosto) e abaixo o da Academia. $\mathrm{Na}$ contracapa, trechos de textos críticos e no espaço reservado ao código de barras os créditos institucionais. Por ter sido financiada, a obra não será comercializada e sim distribuída para bibliotecas públicas e pesquisadores.

Luz e sombras (v. 1), de Feliciano Galdino de Barros, é considerado o primeiro romance da literatura mato-grossense, publicado em edição única no Rio de Janeiro em 1917. Mesmo faltando algumas páginas (incluindo a final), os editores não hesitaram em republicá-lo. Por ser o primeiro volume, é o que possui maior número de textos explicativos e críticos. "Que escrevemos pouco durante décadas sobre a literatura produzida neste estado, isso é fato inquestionável. Que lemos menos ainda também, [...]" justifica Walnice Vilalva (2008, v. 1: 17). João Antonio Neto observa que, "nossa literatura, fora das obras históricas, esteve mais para a poesia, do que para a prosa de ficção [...] salvo se aqui incluíssemos a Inocência, de Taunay (1872), que se passa em Mato Grosso (do Sul)" (2008, v. 1: 29). Curiosamente, a coleção reservou apenas dois volumes para a poesia. Lobivar Matos comparece com seus dois únicos livros compilados no volume 3 e Vozes femininas traz duas poetas e uma cronista.

Sobre o romance em questão. É provável que seja a primeira vez, na literatura brasileira, em que a maçonaria foi apresentada como vilã. Isso se manifesta da seguinte forma: a perseguição aos católicos e o desejo de extinção da Igreja aparecem como projeto da maçonaria apontado pelo narrador. Os valores religiosos se interpõem nos conflitos vividos por Dom Amarante (o maçon que veio da Europa com uma única missão); Flávio (o irmão cooptado pela maçonaria e que deve ajudar na missão de matar seu irmão mais velho, Cristóvão, o desertor); o patriarca Nelson (defensor da religiosidade e da moralidade) e Clarinda (cobiçada jovem de quatorze anos apresentada pelo narrador como uma mistura de Inocência com as mais puras personagens femininas do romantismo). Já na primeira epígrafe é citado o Apocalipse, cap. 13, versos 1, 2, 3 ("E vi subir do mar uma besta que tinha sete cabeças e dez cornos..."). Daí para frente o que se vê são inventivas para que esse terror se manifeste. É um romance que valeu a republicação tão-somente por ter sido o primeiro. $\mathrm{O}$ jogo entre verdade e mentira não segura por muito tempo o leitor.

Mirko (v. 2), de Francisco Bianco Filho, publicado pela primeira vez em 1927, no Rio de Janeiro é bem diferente. Destaque para a tela "Fazenda" de 
Joana Castrilon. A edição atual começa com um riquíssimo texto de Walnice Nogueira Galvão intitulado "O resgate de Mirko". Ela observa que "é sobretudo da imbricaşão de Naturalismo com Regionalismo, com laivos de Romantismo, que surge Mirko. Mais naturalista que regionalista, mais regionalista que matogrossense [...] desarma a expectativa de costumes [...]" (2008, v. 2: 7). Igualmente merecem registro as considerações filológicas de Manoel Mourivaldo Santiago Almeida acerca da edição de Mirko. Novamente, recomenda-se ler a obra primeiro.

Mirko conta as peripécias amorosas vividas por um jovem de dezessete anos. Este é seduzido por Leda desde as primeiras páginas. Há vários elementos que prendem a atenção do leitor: o batuque afro e sensual da festa de S. João; as quadras populares de Sucupira; a atuação do vilão Luciano e o modelo romântico de personagem feminina de Iara - por quem ele finalmente se apaixona. Estes ingredientes sustentam a eficiente narrativa. Por ser injustamente acusado por um crime que não cometeu, o jovem Mirko acaba tendo que fugir da cidade e atinge um estado de demência amorosa, voltando a uma breve lucidez somente após a morte da amada. Trata-se de um Romeu e Julieta às avessas, com tinturas naturalistas e regionalistas, como bem observa Walnice Galvão.

Areôtorare/Sarobá (v. 3), de Lobivar Matos, foram publicados pela primeira vez em 1935 e 1936, respectivamente, no Rio de Janeiro. Registra-se que o primeiro livro de Manoel de Barros, contemporâneo de Lobivar, sairá somente em 1937. Lobivar escreveu os poemas do primeiro livro quando terminou o ginasial aos dezoito anos. Na prática, foi o primeiro modernista assumido a fugir dos liames do parnasianismo e a adotar versos livres e brancos em Mato Grosso. Destaca-se a tela "O índio" de Mari Bueno. Em um texto intitulado "Um precursor precoce e rebelde", Carlos Gomes faz uma retrospectiva crítica para quem nunca ouviu falar ou leu poemas de Lobivar Matos. Nesse sentido, vale a pena ler sim o maior texto crítico de toda a coleção (preferencialmente depois de lidos todos os poemas).

O primeiro livro possui uma literariedade maior do que o segundo. Isso pode ser observado desde o título (palavra de origem indígena). Um trecho de "Destino do poeta desconhecido": "Eu sou o poeta desconhecido/[...] A ilusão é minha amiga e meu consolo./[...] A vida me embriaga e me aborrece." (2008, v. 3: 65). Possui uma tintura autobiográfica. Mas não é só isso. A preocupação social aparece em "Homens e pedras": "De vez, em quando um mulato descansa o malho/ e passa o dedo grosso na testa enrugada./ Ouve-se, então, um tinido de aço/ que batesse, em cheio, num bloco 
de pedra./ É o suro do mulato que se cristaliza em aço. [...] O sol é um martelete de ouro perfurando o esapaço!' (2008, v. 3: 69). Assim como os motivos populares em 'São João": "[...] Agora, de longe em longe,/ ouve-se o barulho de um traque retardatário,/ de um foguete/ perdido/ que explode/ tísicamente/ no ar. Vai clareando, amanhecendo./ Como era festivo o São João na minha terra! (2008, v. 3: 90). No romance Mirko, é na festa de São João que o personagem se encanta pela primeira vez por Leda. Outro elemento típico do sertão que aparece é o "Garimpeiro": "O mundo? O mundo é um garimpo, / garimpo conbecido que não dá mais nada,/ onde todos nós, garimpeiros de quimeras/ [...] e onde encontramos, só, depois de tantas lutas!/ cascalhos de ilusões... e nada mais. (2008, v. 3: 94). O lirismo também crepita no poema "Queimada", assunto ainda hoje bastante delicado na região.

Sarobá é a denominação de um bairro de negros, em Corumbá (MS): "Bairro de negros, / mulatas sapateando, parindo sombras magras, / negros gozando, / negros beijando,/ negros apalpando carnes rijas, / negros pulando e estalando os dedos/ em requebros descontrolados, / vozes roucas gritando sambas malucos/ e sons esquisitos agarrando/ e se enroscando nos nervos dos negros. / / Bairro de negros, / chinfrim, bagunça,/ Sarobá.” (2008, v. 3: 112). Igualmente aqui vale remeter ao Mirko, que alucinado assiste a uma batucada. Misturam-se ritmos dissolutos em um ambiente meio naturalista como em " $\mathrm{Mu}$ lata Isaura": "[...] cuidado com o filho da patroa./ Você pensa que ele gosta de você./ Não gosta, não, boba. [...] Ele chama você no quarto dele,/ despe você com palavras bonitas,/ acende em você a fogueira da carne e da volúpial e depois..." (2008, v. 3: 128). E em "Sexo", há as presenças do "menino-galo", "menino-bode", "menino-bezerro" e "meninocachorro" em um autêntico processo de antropomorfização poética.

Piedade (v. 4), de José de Mesquita, foi publicado pela primeira vez, em 1937, em Cuiabá. De todos os romances da coleção, é o mais elaborado do ponto de vista literário. A capa traz a tela "Yasmin e o pássaro" do conceituado artista plástico Sebastião Mendes. Todos os ingredientes presentes na narrativa conduzem a uma boa leitura. Este é um dos escritores mais fecundos do estado, tendo escrito mais de trinta livros. Apesar de o título remeter a uma personagem feminina, demora um pouco para que ela efetivamente apareça/cresça aos olhos do leitor. Dramas familiares e amorosos cercam a família de Paulo. Piedade é sua prima por quem ele se apaixona - mas não a escolhe de imediato - apenas depois que sente que sua saúde está comprometida. Entra em ação a resignação amorosa e uma triste e comovente história tecida pelo narrador. Curiosamente, é o volume que possui menor quantidade de páginas críticas. 
Era um poiaeiro (v. 5), de Alfredo Marien, foi publicado pela primeira vez em 1944, em São Paulo. É um romance que não seria romance e sim novela, garante Otoniel Mota, que lhe assinou o prefácio da primeira edição. Reforça essa classificação Dante Gatto, que assina o estudo crítico da nova edição. Na obra não se divisa claramente tal afirmação. Mas, certamente, trata-se de uma narrativa emblemática de um período importante da colonização de Mato Grosso. Joana Castrilon comparece com a belíssima tela "A festa". É um dos romances da coleção Obras Raras que mais destaca o lugar da narrativa em solo matogrossense. Os rios Cuiabá e Paraguai estão presentes, assim como as referências às cidades de Diamantino e Barra do Bugres. Os personagens Brasilino e Teresa vivem um grande amor, que é submetido à provação da condição social do primeiro e, por isso, depende da aprovação do pai dela que tem outros planos para a filha. Gonçalo é o vilão da estória, fazendo lembrar o personagem Manecão do romance Inocência de Taunay, que também tinha a palavra do pai da Inocência. Essa disputa amorosa não terminará bem. O leitor fica bem próximo dos dramas vividos por um poiaeiro. Além de um forte conteúdo histórico há um componente social que puxa a narrativa para um desenlace que já estava anunciado no próprio título (que se inicia por um verbo no passado).

Vozes femininas (v. 6) traz as poetas Amália Verlangieri, Arlinda Morbeck e a contista Vera Randazzo. Mesmo recomendando que o leitor leia primeiro as obras e só depois os textos críticos, não há como negar os textos bem escritos que precedem a cada obra. Verlangiere publicou em diversos periódicos no estado como O Arauto Juvenília, Ganga, Sarã e O Roteiro, mas editou também uma coletânea denominada Poesias. Em "A poesia nasce de novo" ela diz: "Debalde procurar, debalde, / A imitação do lirismo, / Quando até as belas rosas/ Estão manchadas de sangue./ A poesia é o grito louco/ Das mentes em confusão [...]" (2008, v. 6: 43). Na seleção feita pela equipe de pesquisa há pelo menos vinte e sete poemas em que consta a palavra "poema". Nesse sentido, a preocupação com a linguagem e o fazer poético é mais do que evidente. Em "Poema VI" desfia: "Ospés frios, descamados/Lembram raízes verdes/ Trêmulas, no asfalto. / E os lampeões fundeados/ Nas órbitas escuras/São janelas súplices/ De sonho.” (2008, v. 6: 70).

Arlinda Morbeck é a única autora da coleção que não possui dados precisos sobre a sua biografia. É provável que esse mistério não seja culpa dos pesquisadores, Marli Walker observa que "na invenção poética de Arlinda Morbeck, Romantismo e Simbolismo mesclam-se em figuras de luz e sombra, balizando a divisa da 
dúvida e da desilusão." (2008, v. 6: 100). Através de uma poesia simples, Morbeck constrói uma poética do cotidiano, como em "Teu violão": "Cantas... e tua canção/ faz vibrar, com emoção,/ as cordas do coração!’ (2008, v. 6: 114).

Vera Randazzo é a autora que canta em prosa a terra em que vive. Mesmo sendo original de Caxias do Sul, é Cuiabá quem recebe as homenagens da escritora. O primeiro conto "Pagmejera, Pagmejera!" homenageia Marechal Rondon. Mas ela também canta, singelamente, "A minha goiabeira". As crendices populares aparecem de forma cômica em "A simpatia": "Era uma vez. um seringueiro magro e cheio de marcas de variola pelo rosto triste" (2008, v. 6: 228). Mais tarde o seringueiro irá levantar a cabeça e ver que tinha saldo com o patrão e, ainda por cima, esbarra e depois se casa com a filha do mesmo. Vários títulos metonímicos como "A tormenta" e "Crepúsculo" mostram o espírito feminino em conflito. As personagens femininas, aliás, permeiam quase todas suas narrativas de forma intensa. $\mathrm{E}$ a linguagem oral e poética valoriza-se em passagens como: "- Virge, seu sorriso parece a água que corre nas pedras verdes da corredeira..." (2008, v. 6: 257). "O pão" é um dos melhores contos do livro. Bem estruturado e envolvente, ressalta a qualidade dessa prosadora. O leitor tem uma clara noção da arte de fazer pães e fica tão próximo do resultado final que o fermento poético faz crescer a massa do conto na medida e tempo certos.

Caçadores de diamantes (v. 7), de Luis Sabóia Ribeiro, teve duas edições (1945 e 1959), ambas no Rio de Janeiro. Não se trata propriamente de um romance social, talvez se aproxime mais de crônicas do que de reportagens, como quis defender o editor da coleção Obras Raras, Carlos Gomes. Não possui discurso direto. Não há personagens fixos ou mutantes que liguem/participem de um texto ao outro. Mesmo assim, o leitor entra em contato com a linguagem do garimpo. O autor tenta apresentar o espaço geográfico de maneira uniforme. Vale pelo relato das coisas que presenciou e/ou através da memória coletiva.

A finalidade primeira do projeto de pesquisa era estudar e difundir a literatura mato-grossense. Isso efetivamente aconteceu. Agora cabe aos estudiosos se debruçarem sobre esses volumes para deles tirarem novas impressões.

\section{Referências Bibliográficas}

CARVALHO, Carlos Gomes de; VILALVA, Walnice (Org.). Coleção Obras Raras de Mato Grosso. Cuiabá: Academia Mato-Grossense de Letras; Unemat, 2008. 